\title{
The Response of the Millennial Generation Towards the Issue of Ethnic Equality in Indonesia in Tanda Tanya (?) Movie by Hanung Bramantyo
}

\author{
Dyah Eko Hapsari ${ }^{1}$, Rosana Hariyanti ${ }^{2}$ \\ \{dyahekohapsari@ub.ac.id ${ }^{1}$,rosana@ub.ac.id² \\ Universitas Brawijaya, Indonesia ${ }^{1,2}$
}

\begin{abstract}
Because of its diversity, Indonesia, as a large country with a diverse society, has significant advantages. However, heterogeneity has the potential to cause a variety of social conflicts that lead to the nation's disintegration. Tanda Tanya (?), a big-screen film, is one of the depictions of the conflict. Hanung Bramantyo, Indonesia's leading filmmaker, directed this 2011 film production. The story of a diverse social environment in Semarang City is told in this film. The figures depicted are of the Javanese, ethnic Chinese, Muslim, Catholic, and Buddhist ethnicities. The purpose of this research is to find out what the millennial generation thinks about the film's depiction of inter-ethnic equality. The theory employed is the Reader-Response theory, in which the reader's position is crucial to the meaning of the text. The findings show that the respondent groups had differing perspectives on the film's depiction of ethnic equality. The difference in opinion is determined by the society's category. The majority group, the first group of respondents of Javanese ethnicity, tended not to involve their affective side when watching movies. This is due to their repertoire and status as an outsider. This group employs efferent reading in the context of Rosenblatt's Reader Response. The effectiveness of film media in conveying messages about ethnic equality is thought to be less effective, and the millennial generation prefers social media platforms with lighter content that reach more people. The study's findings demonstrate the role of readers in interpreting text and social media platforms with light and easy-to-understand content is more desirable.
\end{abstract}

Keywords: Ethnic Equality, Film, Millennial Generation, Reader Response, Repertoire

\section{Introduction}

Indonesia, a vast nation with a heterogeneous culture, has great advantages because of its diversity. On the other hand, however, heterogeneity also has the potential to generate various social tensions that lead to the disintegration of the country. One of the biggest ethnic conflicts in Indonesia coincided with the advent in May 1998 of major changes in state life, marked by riots. In this event, ethnic Chinese suffered the worst impact as a result of anti-Chinese sentiment. One of the photographs of the dispute is taken in a big screen film entitled Tanda Tanya (?). This 2011 film production was directed by Hanung Bramantyo, Indonesia 's leading filmmaker. This film tells the story of a heterogeneous social climate in Semarang Region. The numbers shown are from the ethnicity of Javanese, ethnic Chinese, Muslim, Catholic, and Buddhist.

Several scenes in the film demonstrate how the family is trying to adjust to the local environment, but also receives a negative stigma. This is important to note, particularly in 
relation to how young viewers who are millennials react to this phenomenon. The audience of the Millennial Generation is the generation that was born between 1980 to 2000 . They are called as Millennials because of their closeness to the new millennium and being raised in the more digital age. This generation is influenced by computers and a greater acceptance of nontraditional families and values [1]. This generation is also depicted as the generation that was born during the dawn of a digital era and a smaller interconnected world due to technology, these digital natives spent more than 6 hours/day online and were at the forefront of globalization with access to an unprecedented amount of information, opinions, and cultures [2]. Further, Timmerman also mentions that millennials are, "more numerous, more affluent, better educated, and are more ethnically diverse" than previous generations. To summarize, this generation actively participates in getting the most up-to-date information on what is going on in their society through the use of technology. This means that they are generally up to date on current social issues, such as discrimination based on gender, race, or ethnicity. This becomes the researcher's primary consideration in positing this generation as an important informant for this study, as their response to the issue of ethnic equality described in the film becomes significant.

The goal of this study is to examine the opinion of the millennial generation on the topic of inter-ethnic equality portrayed in the film by applying Reader-Response theory. The base stone of the theory, I.A. Richards claims that the reader plays a part in the meaning of a very large text, involving personal knowledge and the repertoire of previous texts. Louise M. Rosenblatt also argued that text and readers have a very close relationship in the process of reading the text. Reader Response Theory emphasizes two things: (1) the effect of literary texts on readers; and (2) the role of the reader in shaping the meaning of the text is very important.

The response of the audience in this study is also further drawn to the degree of efficiency of film media as a messenger of ethnic equality problems, along with formats and media that are more in line with the characteristics of the millennial generation. This aims to obtain an image of the proper portrayal of the media so that they can take on board this critical topic.

\section{Review of Related Literature and Research Method}

This research uses reader response theory as a framework for responding to problem formulations. Reader Response gives the reader a central role in reading the work. This idea has been yielded as a study of literary works. However, as Stokes [3] explained in her book How to Do Media and Cultural Studies that films, television shows, musical pieces or artifacts displayed in museums can be regarded as text. The paradigms that are frequently used in text analysis are usually drawn from literary studies. Many approaches to media and cultural development have something to do with the study of novels and other literary works. This theory is then used to discuss research problems with the object of the analysis in the form of a film. This theory calls into question the nature of a literary text without the intervention of readers who read and interpret the work. In the extreme, this theory sees that a literary text would not exist if no one reads it and eventually the literary text has no meaning whatsoever.

There are many literary experts who express their opinion on the role of the reader in the interpretation of literary texts. I.A. is the figure that can be used as the base stone. Richards, who argues that the reader plays a part in the meaning of a text by involving personal knowledge and the repertoire of previous texts. Louise M. Rosenblatt further claims that text and readers have a very close relationship in the course of reading the text: 
The reading process involves a reader and a text. Both the reader and the text interact or share a transactional experience. The text acts as a stimulus for eliciting various past experiences, thoughts, and ideas from the reader, those found in both our everyday existence and in the past reading experiences. Simultaneously, the text shapes reader's experiences, selecting, limiting, and ordering the ideas that best conform to the text. Through this transactional experience, the reader and the text produce a new creation, a poem [4].

Rosenblatt sees the mutual relations between the text and the reader, and also sees the possibility of the influence of the text to form the reader's experience. It has also reported that "the reading of any work of literature is, of necessity, an individual and unique occurrence involving the mind and emotions of some particular reader and a particular text at a particular time under particular circumstances" [3]. This point reinforces the notion that reading a text is influenced by the individuality of the reader who is in a certain time and circumstances.

This study was conducted by interviewing 4 (four) respondents representing the millennial generation. The four respondents aged 19-21 consisted of two people from the Chinese ethnic group and two from the non-Chinese ethnic group (especially Javanese). The selection of respondents was made by considering that they represented two classes, namely ChineseIndonesian and Javanese, so that responses would be given on the basis of their respective backgrounds. In addition, they reflect the millennial generation in terms of age.

Cintysa and Saktiningrum [5], conducted previous research related to this study with respect to formal objects. The goal of this study is to determine the characteristics that readers expect from Gothic-Romantic work, and to identify why Stephenie Meyer's Twilight is more widely read compared to Kami Gracia and Margaret Stohl's Beautiful Creatures by Comparing the elements and using reader response theory.

The next thesis is a review by Hesti [6]. This study shows the influence of reading the Harry Potter novel series on the Harry Potter generation, a generation that experienced adolescence from 2000 to 2010. The purpose of this study is to see the impact that occurs, directly or indirectly, on readers of this series from the point of view of the reader and to apply the theory of reader-response.

Both of these experiments related to this research in terms of the research methodology model, although the purpose of the analysis and the research goals were different. The first study attempts to demonstrate the reader's preference for a literary genre by examining its underlying elements, while the second study explores how literary texts influence the reader's view of meaning. The purpose of this study is to disclose the reader's response to the issue of ethnic equality in Indonesia by applying clear criteria to respondents.

\section{Result and Findings}

\subsection{The Portrayal of Ethnic Plurality in Indonesia in Tanda Tanya (?) Movie}

\subsubsection{Movie Themes and Reality Dramatization: A Majority Perspective}

The debate on this point of view is very important when it comes to the social status of respondents from the Javanese community, which is one of the largest ethnic groups in Indonesia. As one of the largest ethnic groups in Indonesia, Javanese does not only comprise a large number of people, which, of course, has significant political impact. Majority classes all 
over the world typically have a strategic role in state life. Typically, this party has political bargaining power and can determine the course of government policy. Because of its very decisive role, this community also enjoys advantages in political and social contexts.

From the answers of the two student respondents who came from the Javanese ethnicity, the two respondents replied with opinions that appeared to be similar. Both respondents from the Javanese community, which is one of the largest ethnic groups in Indonesia, agree that this film attempts to reflect the reality of minority and majority ties. According to them the plot that is made in the film is too sharp and seems to be dramatic. In their daily observations, tensions between ethnic groups in Indonesia, in particular Chinese Indonesians and Javanese, have not reached a point where conflicts have arisen openly. Prejudice toward ethnicity based on the stereotyping of the Chinese Indonesian community does occur among the members of the community, but it is confined to peer-to-peer gossip and is not part of a larger construction. If one or two people from the Chinese Indonesian ethnic community are perceived to have attitudes in line with the negative stereotypes labeled by that ethnic group, the other groups of society, according to the respondent, will only stop at the labeling stage and not lead to a more open confrontation that has the potential to carry emotions from both sides to the whole group. Cited from the interview with the respondent 1:

From my personal experience, the difference between the Chinese ethnic group and the other ethnic groups here is not obvious to me because we still have the word 'tolerance', so people still prefer to speak behind their backs. So, I used to have friends who have different concepts with non-Muslims or people with different ethnic backgrounds... I didn't dare say about the differences right away. But if you speak about all this, it's like a handful of assumptions. Typically, it's to prevent longlasting issues. We normally use 'jokes' rolled like that... So maybe that will be an excuse not to get tangled up in the law later (Interview with Respondent 2 on September 8, 2020).

Nor is this argument very different from the response of respondent 2 of the same ethnic group:

Oh, maybe so, Mom. In my view, the fights in the film are just manifestations. In real life, more indirectly, like trade rivalry, there must be disputes of this kind. It's more discreet, subtler and less overt than in the film. I don't agree, ma'am, in terms of friction. Supposedly, if we reflect in everyday life, it's not that sharp. We don't have to fight all the time every time we meet, and people have also acknowledged the situation that we really have to respect each other (Interview with Respondent 1 on 3 September 2020).

The responses of the two respondents were interesting in the light of their rejection of an open ethnic conflict. These two respondents came from a millennial generation born in the late 1990s or early 2000s who of course did not encounter inter-ethnic riots in May 1998 involving Chinese Indonesians who were considered to be non-indigenous and non-Chinese Indonesians who were considered indigenous. This means that the potential for inter-ethnic tension in Indonesia has emerged and is likely to recur in the future. Since this generation has not witnessed and experienced these events, the prospect of an open conflict between ethnic groups in Indonesia is not something that is imaginary, not actual, not ideal. 
The debate on this point of view is very important when it comes to the social status of respondents from the Javanese community, which is one of the largest ethnic groups in Indonesia. As one of the largest ethnic groups in Indonesia, Javanese ethnicity does not only comprise a large number of people, which of course, has significant political impact. Majority groups all over the world typically have a strategic role in state life. In general, this party has political bargaining power and can determine the course of government policy. Because of its very decisive role, this community also enjoys advantages in political and social contexts. Wildman and Davis [7] said:

Members of the privileged group gain many benefits by their affiliation with the dominant side of the power system. Privileged advantage in societal relationships benefits the holder of privilege, who may receive deference, special knowledge, or a higher comfort level to guide societal interaction. Privilege is not visible to its holder; it is merely there, a part of the world, a way of life, simply the way things are. Others have a lack, an absence, a deficiency (p. 881).

Due to its exceptional position, government policies appear to support the greatest number of voters. This situation is encountered constantly, from one generation to the next, which ultimately forms a status quo and generates a perspective that this condition is ideal.

\subsubsection{Movie Themes and Scratches of the Old Scars: A Minority Viewpoint}

The response was significantly different from the second group of respondents from Chinese Indonesians. The two respondents usually argued that the film still usually presented Indonesian everyday life in the light of inter-ethnic relations, but then they corrected it a little emotionally that it was just part of it, not thoroughly explaining the unpleasant treatment that continues to happen in a small way. In addition, Respondent 3 said that when he was watching the film, he had passed some parts of the film that he felt unable to see. This means that this respondent is emotionally carried away by the plot of the film, particularly in those sections where Chinese Indonesian figures are treated less favorably by figures from other ethnicities:

Um, actually, this movie has a lot of messages that you can get, but I watched it a little rough, ma'am. I figured, "How come it's like this" How come I watched it but I couldn't watch a full-length movie, yet there were sections I missed because I couldn't even watch it the scene where there was one male character- Hendra runs into a group of Muslims and they're almost fighting on the street. The Muslim teenagers said he was slanting eyed, and if I'm not mistaken, Hendra backed fire it by calling them "terrorists". The scene was like my own experience in life... (Interview with Respondent 3, 9 September 2020).

This shows that the emotional side of the respondent is touched when he watches this film, particularly when he witnesses a character who is himself suffering unpleasant treatment. Respondents place themselves in one of the ethnic groups appearing in the film. The two respondents broadly said that Tanda Tanya (?) movie still generally depicted Indonesian everyday life in the light of inter-ethnic relationships, but then they corrected it a little emotionally that it was just part of it not completely depicting the negative treatment that continues to happen in a small way, such as verbal abuse of the physical attributes they have. It turns out that this disparity in physical appearance is very significant. Racial distinctions can 
decide the role of a group in the structure of society, as explained in Hoon (2012, p. 174): Race is a marker of identity politics, which is the fundamental concept of social organization and identity creation that induces people to behave in certain ways. Racial markers have an effect on the way people interpret, communicate and construct the rationalized other.

The other factor, which was also very significant, was expressed by the two respondents, namely the political event referred to by the two respondents, namely the candidacy of Basuki Tjahaja Purnama (Ahok) when he stumbled on the issue of religious blasphemy. Ahok's political incident turned out to be capable of re-energizing the feelings of non-Chinese ethnic groups to treat Chinese Indonesians unpleasantly. Ahok is supposed to represent the opinion of all ethnic members, which is not true of course. The Chinese people were already oppressed during the New Order, so that they did not have many opportunities for community activities. The Chinese were marginalized and stigmatized. Marginalization because the Chinese were only allowed to participate in economic operations and did not join the bureaucracy in the army.

The second group of respondents, as members of the minority group, has different responses to the messages conveyed in the film. This is because their life experiences and repertoire are distinct. While the idea of ethnic equality seems to be the same as articulated, the second group of respondents seems to be negative and seem to argue and even protest that the principle has not been completely applied in Indonesia. This is due to their place as a minority group facing prejudice, an insider group. The affective side of this second group is more involved in reading the text of the film. This is demonstrated by their view that this film is either used as a guide or educational tool for ethnic equality, but in reality, it is not enough to remove the agony of those who experience prejudice in their everyday lives. The story is perceived to be too perfect. This argument is the same as for the first group of respondents, but from a different pole point. The first group of respondents said that certain aspects of the film scene were too dramatized, suggesting that what was depicted in the film was too much; while the second group of respondents said that some of the scenes in the film displayed just a few negative treatments for their ethnicity.

In her explanation of how the reader plays a very important role in the process of reading the text, Rosenblatt stresses the presence of a transaction process between the reader and the text. The transaction method requires two separate reading, efferent and esthetic stages. Rosenblatt describes a successful reading process as a reading process in which the reader focuses more on what is expressed in the text. In the meantime, in aesthetic reading, the reader is more likely to engage entirely with the elements described in the text. Rosenblatt explicitly asserts that:

The aesthetic reader experiences, savors, the qualities of the structured ideas, situations, scenes, personalities, emotions, called forth, participating in the tensions, conflicts, and resolutions as they unfold. This lived-through meaning is felt to correspond to the text. This meaning evoked during the aesthetic transaction constitutes "the literary work", the poem, story or play. This evocation, and not the text, is the object of the reader's "response" and "interpretation" both during and after the reading event [8].

Not only did the two respondents respond to the film from the message articulated by the film on ethnic equality in Indonesia. As members of the community that is portrayed in the film, they are directly active in the discourse on ethnic equality that is part of the film. However, in the sense of the Reader Response Theory, the first group of respondents who have different life experiences from the second group have a different position, so that they have different transaction patterns from the second group, so that they generate different meanings of the same film. This has been clarified by Rosenblatt: 
Every reading act is an event, a transaction involving a particular reader and a particular configuration of marks on a page, and-occurring at a particular time in particular context. Certain organismic states, certain ranges of feeling, certain verbal or symbolic linkages, are stirred up in the linguistic reservoir. From these activated areas, to phrase it most simply, selective attention--conditioned by multiple personal and social factors entering into the situation--picks out elements that synthesize or blend into what constitutes "meaning". The "meaning" does not reside ready-made in the text or in the reader, but happens during the transaction between reader and text [8].

That the reader, the respondent, while watching the film, interacts with the film text, which includes all their awareness of the meaning provided by the film and produces a response that appears to include more of their feelings, since the respondent's range of interactions in daily life receives less favorable treatment from their community in terms of their social category. In this case, a transaction is made between the text (film) and the reader (audience-respondent) that completes the transaction. Rosenblatt proves that the New Criticism point of view, which emphasizes the central role of the text and the writer, does not always take place in the process of esthetic reading. Rosenblatt positions the reader as a complete individual, complete with personal knowledge of the social category when reacting to the text. It is possible to have a complete tension between the intention of the author and the reception of the reader, which is very common in a literary context.

\subsection{Issues of Ethnic Equality through Media}

\subsubsection{Widescreen Movies}

With regard to the efficacy of the film as a conveyor of the message of inclusion, based on the results of interviews with respondents, all of them argue that Tanya Tanya's feature film is very effective in raising the question of diversity in society, both ethnic and religious diversity. The visualization aspect that characterizes the film is the first point that makes it easy to absorb. Visualization helps audiences to get a complete picture of the problems being discussed. Next is the factor of an interesting story line, as well as the support of the factor of describing situations and objects that are close to reality in everyday life. One respondent clarified that he was not interested in the title of the film at first. However, after watching it little by little, the respondent was really interested and even watched it twice. This intriguing aspect is also reinforced by the factors describing circumstances and objects that are similar to reality in daily life. The respondent clarified that the phenomenon of ethnic and religious diversity coexisting in film society has occurred in real life, as reported by another respondent that: “... If we live side by side and like it or not, there have to be other feelings, there are other races that we have to adapt and respect". (Interview with Respondent 4, September 7, 2020). Things such as Chinese restaurants and others are very similar to everyday life. This makes it easier for respondents to consider the concerns that have been posed.

\subsubsection{Alternative Media}

Millennials living in the age of Industrial Revolution 4.0 are frequently referred to as digital natives. This term refers to the generation that arose in 1990, where technology has been a part of life since birth. They are typically exposed to various digital devices and channels on the network (online) for communication and access to information. The availability of these numerous outlets has made them a generation that is not as technology-savvy as their 
predecessors, the generation of Digital Immigrants. In his paper, Prensky [9] identifies a number of accents that are characteristic of this generation and at the same time distinguishes them from the previous generation.

Digital Natives are used to receiving information really fast. They like to parallel process and multi-task. They prefer their graphics before their text rather than the opposite. They prefer random access (like hypertext). They function best when networked. They thrive on instant gratification and frequent rewards. They prefer games to "serious" work.

Therefore, some remarks were made by the respondents, in particular concerning the manner in which the delivery was considered too heavy and less comfortable. Linked to this weakness, the respondents suggested alternatives to different types of media, channels and formats that were considered more suitable to their characteristics. Television and social media are alternate spaces where they can enjoy a lighter and more realistic presentation of any topic.

\section{Conclusion}

This research eventually leads to the conclusion that the respondent group, the majority ethnic group, can be said to be more idealistic in view of the issue of equality between ethnic groups in Indonesia as seen in the film. The pace of the plot is claimed to be a dramatization of the everyday life of pluralism in Indonesia, which in fact reveals only a small part of the harsh reality of the Indonesian-Chinese ethnicity. Different items have been discovered by the Indonesian-Chinese respondents who appeared to be emotionally active as a result of their experiences of prejudice and unpleasant treatment in their everyday lives. On the presentation side, the respondents decided that films can be an important tool for increasing consciousness of ethnic equality. However, according to their characteristics, the millennial generation has preference for other media outlets that are light and entertaining.

\section{References}

[1] T. W. Heggie, "Lake tourism fatalities: a 46-year history of death at Lake Powell," J. Travel Med., pp. $1-5,2018$

[2] L.-V. Cox, "Understanding millennial, Generation X, and Baby Boomer preferred leadership characteristics: Informing today's leaders and followers," 2016.

[3] J. Stokes, How to do media and cultural studies: Panduan untuk melaksanakan penelitian dalam kajian media dan budaya. Bentang Pustaka, 2006.

[4] C. Bressler, "E. 1999. Literary Criticism. An Introduction to Theory and Practice." New Jersey: Prentice Hall, Inc.

[5] S. Cintysa and N. Saktiningrum, "Comparative Research on Popular Literature: A ReaderResponse Critic on Stephenie Meyer's Twilight and Kami Garcia and Margaret Stohl's Beautiful Creatures," Universitas Gadjah Mada, 2015.

[6] K. HESTI, "The Influences of Reading J.K. Rowling's Harry Potter Series on the Life of Indonesian Readers: A Reader Response Examination." Universitas Andalas, 2018.

[7] S. M. Wildman and A. D. Davis, "Language and silence: Making systems of privilege visible," St. Cl. L. Rev., vol. 35, p. 881, 1994.

[8] L. M. Rosenblatt, Writing and reading: The transactional theory, no. 416. University of Illinois at Urbana-Champaign, 1988.

[9] M. Prensky, "Digital natives, digital immigrants part 2: Do they really think differently?," Horiz., 2001. 